\title{
Memória, fotografia e feminismos na contemporaneidade: experiências e reflexões de mulheres fotógrafas no Cariri-CE
}

\author{
Memoria contemporánea, fotografía y feminismos: experiencias y \\ reflexiones de mujeres fotógrafos en Cariri-CE
}
Contemporary memory, photography and feminisms: experiences and reflections of female photographers in Cariri-CE

Emanoella Callou Belem ${ }^{1}$

Luis Celestino França Júnior ${ }^{2}$

\begin{abstract}
Resumo
Considerando a imagem a partir de sua função documental e partindo da observação de lacunas no registro e reconhecimento do trabalho de mulheres na fotografia, os objetivos desta pesquisa são: conhecer a percepção de fotógrafas sobre atravessamentos da questão de gênero na idealização e exposição de corpos femininos e relatar a experiência da primeira Mostra de Mulheres Fotógrafas do Cariri enquanto espaço de (re)construção da memória da produção fotográfica de artistas do território. Na trajetória da pesquisa realizada de 2018 a 2020 baseou-se nas epistemologias feministas e empregou-se como procedimentos de coleta a realização de entrevistas exploratórias e a aplicação de questionário eletrônico. Para análise de dados empregou-se a análise de conteúdo das informações produzidas/coletadas por meio das entrevistas e questionários. Ressalta-se entre os resultados: os avanços e retrocessos apresentados pelas interlocutoras acerca dos pontos relacionados à exposição e idealização de corpos femininos, a relevância da I Mostra de Mulheres Fotógrafas do Cariri, por ter sido um espaço de encontro e visibilização das fotógrafas do território, que além da qualidade técnica e da sensibilidade artística, construíram a partir da pluralidade de perfis e experiências das participantes uma (re)construção da história e memória local.
\end{abstract}

Palavras-Chave: Fotografia; Gênero; Memória; Feminismos.

\section{Resumen}

Considerando la imagen desde su función documental y a partir de la observación de lagunas en el registro y reconocimiento del trabajo de las mujeres en la fotografía, los objetivos de esta investigación son: conocer la percepción de los fotógrafos sobre el cruce del tema de género en la idealización y exposición de los cuerpos femeninos e informar sobre la experiencia de la primera Exposición de mujeres fotográficas de Cariri como un espacio para (re) construir la memoria de la producción fotográfica de artistas en el territorio. En la trayectoria de la investigación realizada entre 2018 y 2020, se basó en epistemologías feministas y se utilizó como procedimientos de recolección la realización de entrevistas exploratorias y la aplicación de un cuestionario electrónico. Para el análisis de datos, se utilizó el análisis de contenido de la información producida / recopilada a través de entrevistas y cuestionarios. Destaca entre los resultados: los avances y contratiempos presentados por los interlocutores sobre los puntos relacionados con la exposición e idealización de los cuerpos femeninos, la relevancia de la I Exposición de Fotólogas de Cariri, por haber sido un espacio de encuentro y visibilidad para los fotógrafos del territorio quienes, además de la calidad técnica y la sensibilidad artística, construyeron a partir

\footnotetext{
${ }^{1}$ Mestranda em Biblioteconomia; Servidora técnica da Universidade Federal do Cariri - UFCA, Juazeiro do Norte, Ceará, Brasil; emanoella.callou@ufca.edu.br.

${ }^{2}$ Doutor em Comunicação; docente da Universidade Federal do Cariri - UFCA, Juazeiro do Norte, Ceará, Brasil; luis.celestino@ufca.edu.br.
} 
de la pluralidad de perfiles y experiencias de los participantes una (re) construcción de la historia y la memoria local.

Palabras claves: Fotografía; Género; Memoria; Feminismos.

\begin{abstract}
Considering the image from its documentary function and starting from the observation of gaps in the registration and recognition of the work of women in photography, the objectives of this research are: to know the perception of photographers about the crossing of the gender issue in the idealization and exposure of female bodies and to report the experience of the first Cariri Women Photographers Exhibition as a space for (re) building the memory of the photographic production of artists from the territory. In the trajectory of the research carried out from 2018 to 2020, it was based on feminist epistemologies and used as collection procedures the conduction of exploratory interviews and the application of an electronic questionnaire. For data analysis, content analysis of the information produced / collected through interviews and questionnaires was used. It stands out among the results: the advances and setbacks presented by the interlocutors about the points related to the exposure and idealization of female bodies, the relevance of the I Exhibition of Women Photographers from Cariri, for having been a meeting and visibility space for the photographers of the territory who, in addition to technical quality and artistic sensitivity, built from the plurality of profiles and experiences of the participants a (re) construction of local history and memory.
\end{abstract}

Keywords: Photography; Genre; Memory; Feminisms.

\title{
1. Introdução
}

A partir da atuação no campo da fotografia e da observação das atividades realizadas nesta área na Região do Cariri tem nos sensibilizado a pouca visibilidade das fotógrafas no território, enquanto autoras e curadoras de exposições e ministrantes em cursos, eventos, coletivos, projetos e grupos. O que mobilizou reflexões acerca das questões de gênero que estão inseridas na experiência de "ser fotógrafa".

Considerando a imagem a partir de sua função documental e partindo da observação de lacunas no registro e reconhecimento do trabalho de mulheres na fotografia, os objetivos desta pesquisa são: conhecer a percepção de fotógrafas sobre atravessamentos da questão de gênero na idealização e exposição de corpos femininos e relatar a experiência da primeira Mostra de Mulheres Fotógrafas do Cariri enquanto espaço de (re)construção da memória da produção fotográfica de artistas do território.

A pesquisa se realiza no Cariri Cearense, Região que atrai fotógrafas(os) do mundo afora para registrar romarias em Juazeiro do Norte e festas populares como a de Santo Antônio, na cidade de Barbalha. Como exemplos dessas(es) fotógrafas(os) facilmente lembrase de homens que registraram a Região e que tem trabalhos premiados em exposições nacionais e internacionais: Allan Bastos, Tiago Santana, Walter Firmino, Augusto Pessoa, Rafael Villarouca, e outros. Contudo, o mesmo não acontece quando se procura substantivos femininos, seus registros não são frequentemente premiados e os nomes menos presentes em 
sites, exposições, etc. Ainda assim pode-se citar Telma Saraiva e Nívia Uchôa como fotógrafas vanguardistas e mais reconhecidas.

A estrutura do artigo é composta, além desta introdução, por uma seção intitulada Metodologia onde se apresenta nosso posicionamento epistemológico, a delimitação do estudo, a localização da pesquisa, a abordagem e procedimentos utilizados para coleta/produção e análise dos dados. No item 3. Memórias de mulheres: arte, política e apagamentos, apresenta-se o marco teórico-conceitual da pesquisa. Na seção seguinte, I Mostra de Mulheres Fotógrafas do Cariri, apresenta-se a experiência da mostra coletiva e do Foto Síntese e as contribuições para o diálogo sobre a fotografia na Região. No item 5. detalha-se as análises acerca da percepção de fotógrafas sobre idealização e exposição de corpos femininos e as particularidades da atuação de mulheres ao fotografarem outras mulheres, seguido das Considerações Finais.

\section{Metodologia}

A pesquisa segue a abordagem qualitativa, por esta compreender a ação humana como intencional e reflexiva, cujo significado é apreendido a partir das razões e motivos dos atores sociais inseridos no contexto da ocorrência do fenômeno (Márcia FRASER; Sonia GONDIM, 2004). Partindo da preocupação em investigar o papel do gênero nas diversas atividades epistêmicas, trabalha-se com a Epistemologia Feminista, teoria que considera que o preconceito de gênero está infiltrado em diversas áreas do conhecimento humano e um dos seus papéis seria o questionamento e elucidação desses preconceitos (Helen LONGINO, 2012). Quando se pensa a Epistemologia Feminista, não obrigatoriamente se coloca a necessidade haja uma mulher no papel de pesquisadora, mas que o modo de se conhecer e de se fazer ciência foi construído a partir de características tomadas como masculinas.

De acordo com Patrícia Ketzer (2017), a Epistemologia Feminista caracteriza-se por considerar como questões de gênero influenciam nossas concepções de conhecimento, nossas pesquisas e nossas produções científicas. Sendo assim, tem levantado questões relativas a preconceitos de gênero no interior da produção científica nas mais diversas áreas do conhecimento, propondo modificações metodológicas e revisando abordagens conceituais a partir das quais se produz o conhecimento científico.

Retoma-se ainda a categoria "lugar de fala", enquanto busca pelo fim da mediação, de modo a garantir a autorrepresentação discursiva e a busca por protagonismo e voz por parte de 
sujeitas(os) historicamente discriminadas(os) pelos dispositivos de fala (Heloísa HOLLANDA, 2018). Nas palavras de Simone de Beauvoir (2019, p. 12): "Por mais longe que se remonte na história, as mulheres sempre estiveram subordinadas ao homem: sua dependência não é consequência de um evento ou de uma evolução, ela não aconteceu".

O lócus do estudo é a Região Metropolitana do Cariri - RMC, localizada ao sul do Estado do Ceará, o território que se destaca por sua religiosidade, manifestações artísticoculturais e também pelo desenvolvimento econômico registrado nas últimas décadas. A RMC é constituída por nove municípios e criada pela Lei Complementar Estadual n ${ }^{\circ} 78$ sancionada em 29 de junho de 2009, a partir da conurbação pré-existente entre as cidades de Crato, Juazeiro do Norte e Barbalha, conhecida como triângulo CRAJUBAR (Diego NASCIMENTO, 2018).

Dentre os procedimentos de coleta e produção de informações utilizados, destaca-se o uso de entrevistas exploratórias, que de acordo com Raymond Quivy e Luc Van Campenhoudt (2005) podem ajudar a constituir a problemática de investigação e permitem revelar determinados aspectos do fenômeno estudado em que o(a) investigador(a) não teria espontaneamente pensado por si mesmo e, assim, complementar as pistas de trabalho sugeridas pelas leituras.

Utilizou-se ainda o formulário como contato com as interlocutoras e instrumento de acesso aos dados. Em relação ao questionário Sadao Omote, Paulo Prado e Kester Carrara (2005) destacam seu amplo uso dada sua versatilidade e facilidade da aplicação, que pode ser realizada presencial, entregue pelo correio, auto-aplicada e ainda eletrônica, sendo este último um dos modos atuais em que é se utiliza o instrumento em pesquisas quanti e qualitativas.

Como método de tratamento dos dados coletados por meio das entrevistas, formulários eletrônicos e as comunicações com nossas interlocutoras usa-se a análise de conteúdo, um conjunto de técnicas de investigação que através de uma descrição sistemática do conteúdo manifesto das comunicações, tem por finalidade a interpretação destas (Laurence BARDIN, 2011).

\section{Memórias de mulheres: arte, política e apagamentos}

Ainda permanece na sociedade um olhar masculino, que conforme explica Beauvoir (2019), coloca a mulher num lugar que a impede de ser um ser "para si”, pois o mundo não é 
a apresentado para elas com todas as possibilidades. Ao longo da história da arte, observa-se a presença predominante de homens, colocando-os assim, num patamar vantajoso de visibilidade, onde podem delimitar sobre qual percurso as discussões sobre arte seguiam. Danilo Satou (2018) afirma que esse fato é uma consequência da compreensão patriarcal que institui os cânones artísticos ocidentais.

Sobre a questão, Aida Rechena (2011) enfatiza a necessidade de tornar visível o protagonismo feminino aos níveis museal e patrimonial, considerado pela autora como um passo em frente na construção de uma sociedade mais justa, que "aplica os conceitos de igualdade de gênero, de inclusão social e de democracia participativa” (p. 239). Considera-se, assim, de grande relevância conhecer e divulgar os trabalhos destas fotógrafas na contemporaneidade, como uma expressão do reconhecimento de suas obras como memória do território e das fotógrafas como autoras e coparticipes da história local.

Cecilia Fajardo-Hill e Andrea Giunta (2018), apresentam na obra uma exposição que inclui o trabalho de 120 artistas mulheres durante um período de repressão política social em vários países latino-americanos e de embate contra mulheres latinas nos Estados Unidos, destacando um diálogo potente entre as múltiplas estratégias que abordam a politização do corpo feminino e sua liberação, denunciando atos de violência social, cultural e política e questionando o cânone artístico e os sistemas institucionais dominantes.

De acordo com as autoras supramencionadas a própria necessidade de organizar uma exposição sobre gênero evidencia um vácuo no sistema da arte. As autoras afirmam que as mulheres vêm sendo, há séculos, sistematicamente excluídas ou apresentadas de formas estereotipadas e que as oportunidades para resolver este problema são limitadas, pois as estruturas de preconceitos e exclusão ainda prevalecem. Fajardo-Hill e Giunta (2018) pontuam ainda que a invisibilidade está entre os estereótipos que definiram as mulheres artistas na América Latina, não sendo consideradas boas o suficiente ou sendo colocadas nessa posição de invisibilidade quando casadas com artistas reconhecidos. Outro estereótipo das artistas seria o da mulher louca, histérica e vitimizada. Ou ainda que seu trabalho teria menor qualidade, com base na ideia de que sua estética é de mau gosto ou de que as questões que abordam não são importantes.

Paulo Rezzuti (2018) conta detalhes pouco conhecidos sobre mulheres brasileiras no campo da política e arte, e como elas tiveram seus papéis omitidos em importantes processos no Brasil. Para o autor, os(as) historiadores(as) do século XIX não poderiam falar sobre 
mulheres como Maria Felipa de Oliveira, que lutou junto com outras mulheres contra os portugueses durante a Independência brasileira:

\begin{abstract}
Uma história escrita por homens brancos, dentro de uma sociedade escravagista, não daria visibilidade a uma negra, líder de comunidade, pobre, iletrada e que jogava capoeira. Já Maria Quitéria, branca, de classe média e que, obedientemente, voltou à casa paterna após a guerra, era mais fácil de ser explicada como figura feminina no mesmo conflito. Também seria bem difícil explicar o fato de as capitanias hereditárias que mais deram certo, Pernambuco e São Vicente, terem sido administradas por mulheres (Rezzuti, 2018, p. 88).
\end{abstract}

No âmbito das artes no Brasil, o autor questiona como os(as) historiadores(as) poderiam explicar a paraense Julieta de França, uma das primeiras escultoras brasileiras que afrontou a decisão de um júri formado pelos principais nomes das artes brasileiras que desclassificou um projeto seu de monumento num concurso em 1907. Pela sua insubordinação contra o sistema da arte gerido pelos homens, ela pagou com o esquecimento e a paulatina diminuição de trabalhos. Enquanto isso, Nicolina Vaz, uma artista considerada mais "comportada" para os padrões da época, conseguiu diversas encomendas estatais (REZZUTI, 2018).

A historiadora Michelle Perrot afirma ser preciso que a mulher seja piedosa ou escandalosa para poder existir. Esse existir a que a autora se refere é o fato de a mulher ser notada. Ao ser notada, ela passa a ser "digna" de que o seu nome figure nos livros de história, escritos durante séculos somente pelos homens. As memórias de muitas mulheres não foram contadas ou contextualizadas a contento historicamente. Suas memórias, ou seus fragmentos biográficos, ainda descansam em arquivos ou na posse de particulares (REZZUTI, 2018).

Conforme Andréas Huyssen (2014) já que toda lembrança se baseia na mobilização e no apagamento, tanto a memória quanto o esquecimento, são passíveis de múltiplas formas de abuso, assim como ambos podem surtir efeitos benéficos na busca da verdade e na reconciliação. Para Dulcilia Buitoni (2011) pode-se entender o registro imagético como um possível "lugar de memória”. Os lugares de memória, para Pierre Nora (1993) são lugares em todos os sentidos do termo, vão do objeto material e concreto, ao mais abstrato, simbólico e funcional, simultaneamente e em graus diversos, esses aspectos devem coexistir sempre.

Maurice Halbwachs (2013) pensa em uma dimensão da memória que ultrapassa o plano individual, considerando que as memórias de um(a) sujeito(a) nunca são só suas e que nenhuma lembrança pode existir apartada da sociedade. $\mathrm{O}$ autor afirma que as memórias são construções dos grupos sociais, são eles que determinam o que é memorável e os lugares onde 
essa memória será preservada. Assim, a duração de uma memória está limitada à duração da memória do grupo. Isso significa dizer que há necessidade de preservação de elos entre os(as) integrantes(as) de um grupo para que a sua memória permaneça.

No caso das mulheres, suas histórias e memórias ficaram relegadas ao olhar do homem branco. Segundo Djamila Ribeiro (2017) existe um olhar colonizador sobre nossos corpos, saberes, produções e, para além de refutar esse olhar, é preciso que se amplie a análise a partir de outros pontos. De modo geral, diz-se que a mulher não é pensada a partir de si, mas sempre em comparação ao homem.

Diante disso, se faz necessário questionar sobre o espaço que as mulheres ocupam nos museus de arte, no sentido de tentar captar a relação entre mulheres produtoras de arte como pintoras, artistas plásticas, fotógrafas e mulheres representadas em produções artísticas (musas) como modelos de quadros, fotos, esculturas e outros. Avalia-se então, que algumas obras expostas em museus, conjuntamente seus autores e autoras, não elaboram a arte como um meio autônomo ou livre, mas sim como uma representação estrutural de poder. Sendo o museu um dos ambientes onde figuram sistemas, instituições e academias, e muitas vezes, existem interesses financeiros como fator relevante nesse meio (Sylvia MIGUEL, 2017).

Satou (2018) afirma que esse fato é uma consequência da compreensão patriarcal que institui os cânones artísticos ocidentais. A história da arte no Brasil tem grandes nomes de mulheres artistas, que são tidas como referências importantes como Tarsila do Amaral e Anita Malfatti que são as mais memoráveis. Em sequência vêm Lygia Clark, Lygia Pape, Tomie Ohtake, Maria Bonomi, Regina Silveira, Djanira e outras são nomes reconhecidos internacionalmente (MIGUEL, 2017). Ainda assim, este número é reduzido se comparado ao número de artistas do sexo masculino com exposições e destaque internacional.

Durante um debate intitulado Arte e Gênero que aconteceu em 2017 na Universidade de São Paulo - USP sobre exposições do Museu de Arte Contemporânea - MAC, o então diretor Carlos Roberto Brandão, afirmou que se sentia um tanto satisfeito em relação ao número de artistas mulheres presentes. O MAC é tido como um dos grandes espaços para exposições, e é o que tem a maior quantidade de mulheres, são $29 \%$ da coleção, um total de 184 entre os 655 nomes (MIGUEL, 2017).

Contudo, apesar de muitas pessoas se contentarem com tais dados, esses números só demonstram o quanto ainda é preciso dialogar e resistir sobre a temática da representatividade das mulheres nos espaços artísticos. A imagem da mulher não deve predominar como a figura 
inspiradora, musa das obras de arte, ou meras apreciadoras, mas como operantes de uma cena desviante do padrão estabelecido por décadas imposto pela centralização masculina no campo da arte. Por esse motivo, algumas mulheres se juntaram para propor uma reflexão acerca do assunto, com objetivo de resistir e mudar a realidade da dominação masculina, e relutar principalmente as questões entre corpo, mídia e arte numa sociedade de consumo elevado de padrões criados em busca de uma beleza inexistente para as mulheres.

Segundo Maria Ilda Trigo (2018) um desses coletivos de artistas que vem ganhando notoriedade nos últimos anos é conhecido como Guerilla Girls, que é mais conhecido nos Estados Unidos, mas que devido as suas atuações, vem tomando lugar de fala quando se trata dos debates sobre igualdade de gênero e de raça para o ambiente artístico. É um coletivo formado por mulheres que usam máscaras de gorila em público, e teve início no ano de 1985. A princípio as ações eram voltadas em um ativismo popular, espalhando cartazes com conteúdo se utilizando de sarcasmos e mensagens ácidas pelas ruas de Nova Iorque. Do seu surgimento até a atualidade, mais de 55 artistas já tiveram experiências no grupo, que ainda existe como anônimo. A intenção de não mostrar o rosto é interpretada como sendo uma forma de chamar atenção para as causas às quais as mesmas reivindicam, e não para suas aparências, já que é o que justamente o sistema das instituições é visto como patriarcal.

Em passagem pelo Brasil em 2017, as artistas expuseram no MASP, e, um dos cartazes que mais chamou atenção, e que de acordo com Trigo (2018) é compartilhado até hoje nas redes sociais. De forma irônica, as artistas denunciam os abusos que as mulheres são submetidas para obter sucesso como artistas:

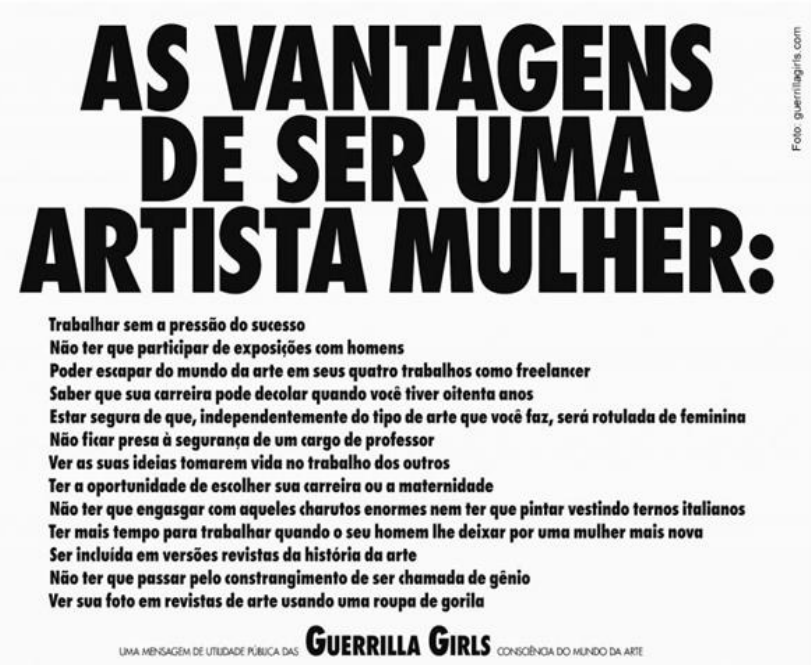

Figura 1 - As vantagens de ser uma artista mulher

Fonte: Guerrila Girls (2017). 
Esse tipo de movimento político que é adquirido através de proposições em forma de arte, é de suma importância no que diz respeito às contestações acerca das desigualdades de gênero nas relações institucionalizadas, como foi colocado neste estudo, o caso dos museus. As práticas de “des-identificação" reportam-se a estratégias que se destinam a impedir o espectador de se identificar com os mundos ficcionais ou ilusórios oferecidos pela arte, pela literatura ou pelo cinema, deste modo provocando uma ruptura na "dança da ideologia" de que se está refém, em nome dos sistemas opressivos de classe, sexismo, heterossexismo compulsivo ou outros posicionamentos e classificações racistas (POLLOCK, 1988).

É válido levantar uma questão que muitas vezes é esquecida pelos dados estatísticos, relacionada à parcela de mulheres que não pôde ter acesso as instituições artísticas, a relação entre gênero, classe e raça interliga uma corrente de opressão que tanto por meios jurídicos estatais, como por intermédio de violências simbólicas se enraizou no desenvolvimento social brasileiro desde a época colonial (Pierre BOURDIEU, 2003) .

Segundo Linda Nochlin (2016), a realidade nas artes, bem como em centenas de outras áreas, é entediante, opressiva e desestimulante para todas(os) as(os) que não nasceram brancos, preferencialmente classe média e acima de tudo, homens. Constata-se assim que houve uma certa apropriação associada a essencialização do corpo feminino, com o interesse voltado à nudez feminina nos trabalhos artísticos produzidos por homens - pode-se observar isso após a quantidade de fotógrafos(as) citados acima com trabalhos com nu feminino -. Entendendo aqui, o corpo como superfície de prática cultural, social e de controle, logo como operante também de poder (Alison JAGGAR; Susan BORDO; Britta FREITAS, 1997).

A figura feminina é associada muitas vezes a ideia do desejo sexual, da beleza purificada, da maternidade ou da desvalorização corporal dependendo do lugar de existência e atuação desses corpos. A nudez associada à arte, consequentemente, a elitização visual do nu, é visto por muitos como algo relacionado à elevação intelectual, a obtenção da arte, como musas despidas. Para outros, existe um julgamento alocado para o pensamento da moral que nega e teme tal nudez.

Outro coletivo de artistas é o FEMEN, surgido na Ucrânia em 2008, como um movimento feminista que luta contra o machismo, o turismo sexual e a prostituição em seu país, este grupo vem aumentando não só sua pauta de questionamento social e de enfrentamento às ações dos Estados, Igrejas e Empresas, como ampliando espacialmente suas 
ações, realizadas em diversos países, procurando reduzir as inúmeras assimetrias nas diversas relações de poder instituídas (Ricardo NOGUEIRA, 2013).

Para as mulheres que compõem o FEMEN, o controle total sobre o corpo da mulher é o principal instrumento de sua supressão; a démarche sexual da mulher é a chave para sua libertação. A manifestação do direito ao seu corpo pela mulher é o primeiro e mais importante passo para a sua libertação. A nudez feminina, livre do sistema patriarcal, é uma escavadora do sistema, manifesto militante e símbolo sacro da libertação das mulheres (FEMEN, s.d.).

O FEMEN (s.d.) pensa e atua na visão ideológica que parte de teorias sextremistas, ateias e feministas. Os "ataques nus" realizados pelo grupo são pelos considerados um "nervo nu", que seria um conflito histórico do sistema da mulher, sua imagem mais à mostra e adequada. No sentido de perceber o corpo nu ativista como um sentimento de ódio que não está disfarçado em conexão à ordem patriarcal e busca por uma estética nova da revolução feminina.

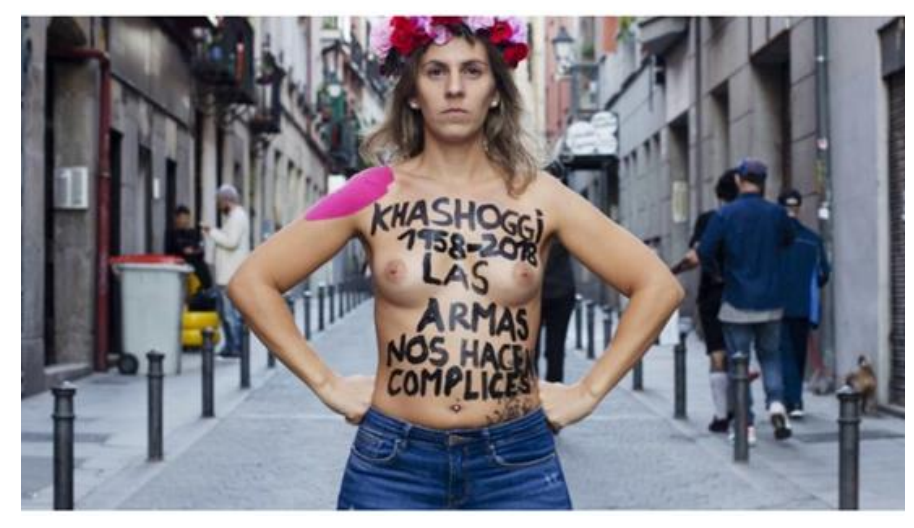

Imagem 1 - Stop Arming Saudi Arabia!

Fonte: FEMEN (s.d.).

Jaggar, Bordo e Freitas (1997) salientam que não essencialmente através da "ideologia", mas por meio da organização e da regulamentação do tempo, do espaço e dos movimentos de nossas vidas cotidianas, nossos corpos são treinados, moldados e marcados pelo cunho das formas históricas predominantes de individualidade, desejo, masculinidade e feminidade.

\section{I Mostra de Mulheres Fotógrafas do Cariri}

A primeira Mostra supracitada foi aberta em 29 de agosto de 2018, na galeria do Centro Cultural Banco do Nordeste Cariri - CCBNB em Juazeiro do Norte. A exposição foi 
promovida pela Universidade Federal do Cariri-UFCA por meio do curso de Jornalismo e da Pró-Reitoria de Cultura - Procult em parceria com o CCBNB, a exposição integrou a programação do IV Foto Síntese, evento de fotografia realizado pela UFCA desde 2015.

A referida Mostra, que compôs a quarta edição do Foto Síntese, foi dedicada ao tema "Corpo e Imagem”, trazendo na sua programação principal debates com mulheres e realização de atividades como oficinas e ainda um passeio ciclístico urbano. As fotografias apresentadas na Mostra possuem entre seus critérios de seleção se tratarem de imagens produzidas exclusivamente por mulheres, de modo a compor nesta seleção o que se pode nomear como memórias de mulheres. Tais imagens são também parte da história da fotografia na Região do Cariri, e, ainda, um trabalho importante para a representação e representatividade feminina na arte.

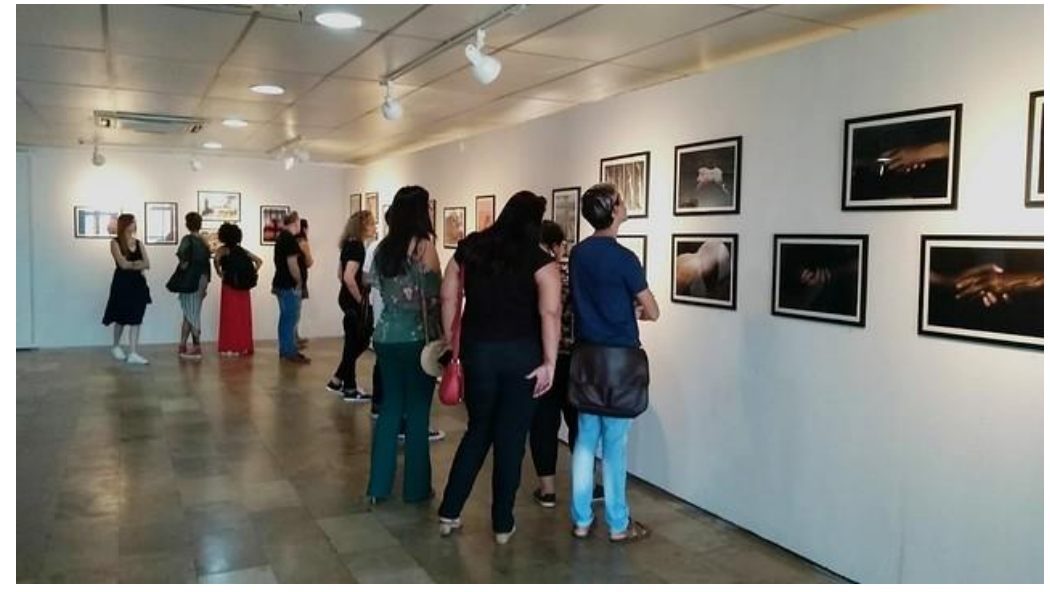

Imagem 2 - Lançamento da exposição

Foto: Emanoella Belém

Durante esta edição do Foto Síntese uma das convidadas, Marília Oliveira, educadora e artista visual, coordenadora do Descoletivo Espaço de Criação - DEC e integrante, junto a Régis Amora, e do Descoletivo - coletivo fotográfico que realiza ações urbanas e exposições em espaços institucionalizados - discutiu o tema dos espaços urbanos e dos corpos que ali transitam, chamando à atenção para situações cotidianas onde as mulheres são privadas da liberdade de transitar em locais públicos devido aos perigos e assédios constantes. A fotógrafa tratou ainda do tema conhecido como Revenge Porn, que é a publicação não autorizada de imagens íntimas, onde o principal alvo são sempre as mulheres.

A ideia de visibilizar o trabalho de mulheres fotógrafas no evento onde surgiu a Mostra de Mulheres Fotógrafas do Cariri, veio da necessidade de levar trabalhos de mulheres 
a espaços como museus e galerias de arte, que são locais que até os dias de hoje ainda possuem maioria masculina em exposições. Essas fotógrafas e suas obras representam, neste trabalho, a história da fotografia de mulheres do Cariri, as histórias e trabalhos de mulheres que nunca foram contados ou destacados anteriormente. Dessas autoras, buscou-se compreender os processos criativos e a posição de ser mulher e fotógrafa no Cariri, colocando-as assim como sujeitas fundamentais da história e memória local.

Atentou-se ao longo da pesquisa para que pelo desejo de contribuir pela visibilidade das mulheres na fotografia, em especial na Região do Cariri não tenha efeito contrário de falar por elas - mesmo fazendo parte desta categoria - tirando o protagonismo das interlocutoras/do grupo pesquisado, como ressalta Gayatri Spivak (2010) que desvela o lugar incômodo e a cumplicidade do intelectual que julga poder falar pelo outro e, por meio dele, construir um discurso de resistência. Agir dessa forma para a autora é reproduzir as estruturas de poder e opressão, mantendo o subalterno silenciado, sem lhe oferecer uma posição, um espaço de onde possa falar e principalmente, no qual possa ser ouvido.

Sandra Almeida (2010) menciona sobre a análise de Spivak acerca da representação, descrevendo que há uma relação intrínseca entre o "falar por" e o "re-presentar", já que nos dois casos há a pressuposição de um falante e de um ouvinte. A autora pondera ainda que o processo de fala se caracteriza por uma posição discursiva, uma transação entre falante e ouvinte e, nesse sentido, conclui afirmando que esse espaço dialógico de interação não se concretiza jamais para o sujeito subalterno que, caso esteja desvinculado de alguém que o dê "legitimidade", de fato, não pode falar.

\section{Análises: percepção de fotógrafas sobre idealização e exposição de corpos femininos}

Um dos pontos que atravessam a construção deste trabalho é a preocupação com a participação - e o modo que ela se deu e se dá - das mulheres no registro da história, nosso protagonismo tantas vezes dá lugar a um papel secundário nas lutas e conquistas sociais, na família, no trabalho e como não podia deixar de ser, na fotografia. Tanto na vida privada quanto na vida pública, na maioria das vezes, as mulheres não recebem o reconhecimento proporcional ao esforço que dispendem em suas funções.

Discute-se ainda a dificuldade da maioria das mulheres em se perceber como fotógrafas e de tratar de modo relevante estes artefatos e como esta complexa relação entre autora e obras se configuram enquanto barreiras para a visibilização do trabalho das mulheres 
na fotografia. Tais questões encontram-se intimamente relacionadas aos papéis de gênero e relações de poder forjadas em nossa sociedade.

Enfatiza-se o grande valor de registrar nossas memórias - seja pela fotografia, pela literatura, escrita acadêmica, história oral, entre outras - para a (re)construção da história e histografia dos territórios em que estejam presentes outros olhares e vozes até então subalternizadas e invisibilizadas: mulheres, pobres, negros(as), moradoras de áreas periféricas, de pequenas cidades, da zona rural, etc.

Abaixo, destaca-se duas categorias dentre as quais foram estudadas a partir das narrativas das fotógrafas que foram respondentes deste estudo.

\subsection{Exposição de corpos femininos nus}

Questiona-se as fotógrafas sobre a exposição dos corpos femininos nus e suas relações com a questão, seja como modelo ou como fotógrafas. Apesar de haver um grande avanço na liberação feminina nesse sentido, percebemos que ainda existe muito medo do julgamento social. Nas respostas às entrevistas e ao nosso questionário, as opiniões foram diversas, mas a grande maioria das fotógrafas participantes assentem que a questão ainda é um tabu, destacando diferentes nuances de acordo com suas experiências.

Sobre a série enviada para a Mostra, que descreve com as imagens as sensações femininas após o sexo, a fotógrafa Lícia Maia afirmou que:

[...] Foi uma barreira que ela [a modelo] venceu, pois por mais que ela fosse super aberta com o corpo dela, para tirar a roupa na frente das minhas lentes, e eu também tinha que vencer aquilo, por ela e por aquele trabalho que eu fiz, que um dia eu precisei e, por tantas outras mulheres, para as mulheres entenderem que o nosso corpo é normal. Que não é tudo bem só um homem tirar a camisa, também é tudo bem a gente tirar a camisa e cada uma tem suas especificidades, não precisamos ter vergonha dos nossos corpos (Trecho da transcrição da entrevista realizada com Lícia Maia).

Jade Andrade diz que a exposição do corpo feminino ainda é um tabu, e que tal exposição é hiperssexualizada:

Basta atinar para a política de gerência de conteúdo nas redes sociais que censura mamilos femininos, por exemplo. Eu já fiz ensaio nu, mas foi a pedido da própria modelo e envolvia toda uma questão de autoacolhimento (sic.), quebra de paradigmas acerca do próprio corpo; então difere da questão que está sendo pautada. Mas me sororizo pelas fotógrafas e modelos que têm dificuldade de fazer e expor esse tipo de trabalho. Também pretendo fazer sobre corporeidade feminina, futuramente (Resposta de Jade Andrade). 
Em resposta ao questionário, a fotógrafa Rejane Lima afirma que não faz muitas fotos de nudez, mas acredita que a resistência não é das modelos e sim da sociedade. Ressalta-se que por viver num mundo onde o corpo feminino é exposto diariamente e na maioria delas de forma idealizada e sexualizada, criando uma espécie de fantasia do corpo feminino sensual, isso gera uma sexualização precoce de meninas e muitos traumas para mulheres adultas. Além disso, as mesmas mulheres que crescem vendo e assistindo esse tipo de exposição são julgadas quando querem expor seus corpos de livre e espontânea vontade. É uma mensagem completamente equivocada, que trata os corpos femininos como propriedade e obriga mulheres a seguirem um padrão de conduta, e que quando não seguem, se tornam culpadas e vítimas pelos ataques que sofrem, como por exemplo o assédio e violência sexual que atinge níveis alarmantes no Brasil.

Neste sentido, Ian Smith (2018) afirma que o nu fotográfico, inspirado na pintura, "englobou o erotismo, a anatomia e a pornografia, bem como o estudo da forma e a identidade de gênero" (p. 19). O autor destaca o trabalho da fotógrafa Ruth Bernard como uma das poucas mulheres que são conhecidas por estudos de nus, "explorando a forma feminina a partir de uma perspectiva menos sexualizada que a da maioria de seus colegas homens" (p. 19).

Contribuem também para a contribuição desta temática Maria da Luz Correia e Carla Cerqueira (2017), as autoras propõem um encontro dos estudos de fotografia com os estudos de gênero, ao evidenciarem a necessidade de pensar o olhar de maneira política, a partir do domínio das ciências da comunicação considerando não apenas as assimetrias de gênero, mas também as de raça, idade, cultura e outras.

Crimes de internet como assédio em redes sociais e abusos como a exposição não autorizada de imagens, demonstram que na maioria dos casos as vítimas são as mulheres. $\mathrm{O}$ termo que ficou conhecido como Revenge Porn designa os casos de disseminação não consentida de imagens íntimas na internet. Buscando trazer novas perspectivas sobre a forma como as políticas que lidam com gênero e intimidade na internet, as autoras Juliana Ruiz, Natália Neris e Mariana Valente (2017) fizeram um mapeamento para compreender diferenças e semelhanças no tratamento da disseminação não consentida de imagens íntimas em 25 países. As autoras analisam a forma como as instituições enxergam e classificam tal problema e como lidam com as relações de gênero desse tipo específico de violência, como, por exemplo, se isto passa pela compreensão de uma violência de gênero - o que identificam como ausente no Brasil. 
Sobre a questão, Yasmine Morais complementa:

Tabu? acho pouco dizer que seja somente um tabu. O corpo da mulher ainda e vestido de formas cruéis de interpretação. O corpo nu feminino visto e fotografado infelizmente abre porta para crimes como o assédio (Yasmine Morais, grifo nosso)

Não apenas por crimes cibernéticos, a violência sexual contra mulheres - e meninas - é um dos maiores problemas sociais do Brasil e uma das expressões do sexismo e da inadequação do sistema capitalista, desigual e excludente. Alguns dados sobre essa questão podem ser consultados nos Atlas da Violência, publicados anualmente - após ampla pesquisa pelo Instituto de Pesquisa Econômica Aplicada - IPEA e o Fórum Brasileiro de Segurança Pública - FBSP. Na edição de 2019 aponta-se que, a cada hora, quatro meninas de até 13 anos são estupradas no Brasil e que do número total de vítimas de violência sexual, 81,8\% são mulheres (IPEA/FBSP, 2019). Houve ainda um crescimento dos homicídios femininos no Brasil em 2017, com cerca de 13 assassinatos por dia. Ao todo, 4.936 mulheres foram mortas, o maior número registrado desde 2007 (IPEA/FBSP, 2019).

Para Ruiz, Néris e Valente (2017) revenge porn ou pornografia de vingança (termo que discordamos) "ganhou grande popularidade internacionalmente a partir dos anos 2010s e é geralmente definido como o ato de um ex-parceiro tornar imagens ou vídeos íntimos de teor sexual públicos online" (p. 01). As autoras discorrem sobre eventos no Brasil e no mundo onde imagens de mulheres foram parar na rede sendo divulgadas não apenas por ex parceiros, mas também por abusadores e até por técnicos de informática que tiveram acesso por meio de computadores de terceiros, sendo assim, definem que:

[...] trata-se de um fenômeno mundial, que pode tomar várias formas - o que faz com que seja importante colocar que, diversas vezes, não há propriamente a figura de um ex-parceiro que tenha motivações para uma "vingança" contra a antiga parceira, ou uma imagem "pornográfica". Por essa razão, acreditamos que a expressão "disseminação não consentida de imagens íntimas" (non-consensual intimate images- NCII) seja mais apropriada (RUIZ; NÉRIS; VALENTE, 2017, p. 02, grifos nossos).

As autoras enfatizam ainda que a popularidade do fenômeno e os danos que causam para as vítimas, como depressão, isolamento social, deslocamentos forçados e suicídios, fizeram com que o assunto fosse debatido na esfera pública e que governos fossem provocados a buscar saídas legais. Em seus estudos elas verificam uma tendência a criminalização enquanto enfrentamento da disseminação não consentida de imagens íntimas, dentre os países estudados por elas, 19 (20, se contar-se o Brasil) apostam ou estão em vias de 
apostarem na via penal como principal resposta ao problema como: África do Sul, Argentina, Austrália (Victoria, South Australia, New South Wales), Canadá (lei federal), Chile, Colômbia, Dinamarca, Escócia, Estados Unidos (em 34 Estados), Espanha, Filipinas, França, Israel, Japão, México, Nova Zelândia, Porto Rico, Reino Unido e Uruguai, ressalta-se ainda países como a Índia e Uganda cujas leis gerais também miram soluções criminais (RUIZ; NÉRIS; VALENTE, 2017).

\subsection{Idealização do corpo feminino e mulheres fotografando mulheres}

Outra temática mencionada nas respostas às entrevistas e questionários aplicados com as fotógrafas durante a pesquisa foi a questão da idealização do que seria um padrão de beleza do corpo feminino. A este respeito Wennyta Lima afirma que:

Encontro no feminino beleza, luta e resistência. Busco durante todo o ensaio ressaltar a beleza e singularidade, inclusive nas imperfeições visto que ninguém é perfeito. Sou contra tratamentos de pós-produção pesados que busquem transformálas em um "corpo ideal" que é irreal (Wennyta Lima, grifos nossos).

Segundo Naomi Wolf (2018) pesquisas indicam consistentemente que a maioria das mulheres que trabalham com sucesso e são consideradas atraentes e equilibradas, nutrem dentro de si pensamentos que envenenam suas liberdades. Diante da imersão nos conceitos de beleza ocidentais, nutrem sentimentos próximos do ódio a si mesmas, tais como as obsessões com o físico e pânico de envelhecer, dentre outros. Para a autora "estamos em meio a uma violenta reação contra o feminismo que emprega imagens da beleza feminina como uma arma política contra a evolução da mulher: o mito da beleza” (p. 21).

Ele [o mito da beleza] é a versão moderna de um reflexo social em vigor desde a Revolução Industrial. À medida que as mulheres se liberaram da mística feminina da domesticidade, o mito da beleza invadiu esse terreno perdido, expandindo-se enquanto a mística definhava, para assumir sua tarefa de controle social (p. 22).

Ainda conforme Wolf (2018) a ideologia da beleza é a última das ideologias que ainda tem o poder de dominar as mulheres e dirimir as conquistas obtidas pelas mulheres a partir dos anos 1970. A autora afirma que tanto o culto da beleza e quanto a juventude da mulher são estimuladas pelo patriarcado e atuam como mecanismos de controle social para evitar que sejam cumpridos os ideais feministas de emancipação intelectual, sexual e econômica. Tais questões seriam justamente as preocupações relacionadas à aparência física, do corpo ao cabelo e até às roupas, que muitas sentem e tem vergonha de admitir. 
Para Wolf (2018) "quanto mais numerosos foram os obstáculos legais e materiais vencidos pelas mulheres, mais rígidas, pesadas e cruéis foram as imagens da beleza feminina a nós impostas" (p. 16). Para a autora, muitas mulheres têm a percepção que o avanço coletivo foi detido e que hoje clima é desanimador. Durante a última década, as mulheres abriram uma brecha na estrutura do poder, mas, ao mesmo tempo "cresceram em ritmo acelerado os transtornos alimentares, e a cirurgia plástica de natureza estética se tornou uma das especialidades médicas de mais rápida expansão" (p. 16).

Há alguns anos o movimento Body Positive (em português: corpo positivo) ganhou força nas redes sociais e posteriormente em campanhas publicitárias. O movimento questiona os padrões de beleza por meio da aceitação da diversidade de corpos. Pode-se encontrar com facilidade atualmente, principalmente no Instagram, por meio da hashtag Body Positive, inúmeras postagens e perfis que buscam influenciar essa diversidade e a relação de amor com o corpo diferente do que ainda é considerado o padrão ideal de beleza.

Como via dessa politização em torno do corpo, o Body Positive levanta bandeiras de aceitação e amor ao próprio corpo como ele é. De acordo com Luciana Arandas (2018), "parte significativa dessa nova visão tem como principal fonte o movimento Body Positive (BoPo), cujo lema principal é a não marginalização dos corpos fora dos padrões estéticos dominantes. Esse movimento consiste em questionar as insígnias dos padrões do corpo por meio da exposição das suas próprias imagens e narrativas de experiências de auto aceitação nas redes sociais" (p. 11).

Em entrevista, Geórgia Nunes cita um pouco de suas experiências, trazendo a questão do empoderamento:

\footnotetext{
Quando elas se veem na foto elas se sentem pessoas mais especiais, pessoas que não mais são pessoas comuns. A sensação que eu tenho é essa, de que quando eu faço um ensaio é como se a mulher tivesse ultrapassado uma barreira, porque, o que sempre acontece, o que me deixa mais feliz, é quando eu ouço assim: "Geórgia, eu estava passando por uma fase tão complicada que isso fez com que eu me valorizasse, com que eu me visse de outra maneira", então o importante pra mim é exatamente isso, e cada vez os trabalhos vão aparecendo e vão aparecendo mais relatos como estes (grifos nossos).
}

Ainda assim sabe-se que o padrão vigente segue causando transtornos a muitas meninas e mulheres, e que este tipo de movimento é apenas um pequeno passo para romper com a enorme quantidade de preconceitos que as pessoas consideradas diferentes enfrentam diariamente. 
As fotógrafas foram questionadas ainda sobre a importância de mulheres fotografarem mulheres. Percebemos, neste ponto uma visão geral entre as fotógrafas de que existe uma aproximação e sensibilidade maior, de iguais que se entendem e se retratam. Percebe-se essa relação como algo que cria uma ligação e fortalece um sentimento de sororidade, pois ao fotografar e ser fotografada também compartilhamos nossas experiências.

Apenas mulheres sabem e reconhecem a vivência do ser feminino nas cidades. Fotografar mulheres e fazê-las sentir-se belas é um processo de desconstrução e reconstrução da imagem e percepção pessoal (Resposta de Wennyta Lima à questão).

Somos geracionalmente ensinadas a não nos compreender como relevantes. É preciso escrever sobre nós, cantar sobre nós, nos desenhar, nos registrar. Nossas vidas, corpos, desejos e memórias importam. Que a fotografia seja um meio de despertar uma visão empática e sororizada sobre nós e entre nós mesmas, que é algo urgente (Trecho da resposta de Jade Luiza).

Eu diria que é mais importante que este ponto específico, vejo a imensa importância de mulheres fotografarem, pintarem, desenharem, cantarem, enfim. De mulheres exercerem profissões que historicamente foram masculinizadas. Após esta possibilidade de acesso, é importante cada uma saber sobre o que querem fotografar e poder exercer este lugar também. Mas obviamente que mulheres se sentem mais seguras com outras mulheres (e que pensando na interseccionalidade), e que isso contribui para que diversos trabalhos sejam feitos com mais qualidade, cuidado e segurança (Resposta da fotógrafa Maria Macêdo).

Durante muito tempo essa linguagem era predominantemente masculina. Esse tempo só mostra o machismo até nas esferas artísticas. Que bom que esse tempo mudou. Hoje as mulheres estão em destaque e que bom. Não é uma questão de competição com os homens, mas, saber que nós podemos também, especialmente porque temos uma sensibilidade diferenciada da do homem, somos capazes de entrar na alma das pessoas apenas com um abraço, um olhar. Isso move o mundo para um lado não convencional, e transcendental (Trecho da resposta de Rejane Lima, grifos nossos).

Eu acho que a gente se sente mais confortável sendo fotografada por outra mulher e que a gente se sente mais confortável fotografando, no caso das fotografas, fotografando mulheres, eu acho que a gente se sente mais confortável conosco, e eu acho que a gente tem um outro sentimento, que a gente não pensa nele quando vai fazer a foto mas que a gente aplica ele, que é o sentimento de que não nos sentimos representadas pelas lentes masculinas [...](Trecho da entrevista realizada com Lícia Maia, grifos nossos).

Para a fotógrafa Lívia Monteiro, algumas barreiras podem ser quebradas com a sensibilidade do olhar feminino sobre o corpo de outra mulher, pois este olhar traz a segurança de estar se expondo entre iguais, sem a objetificação do olhar masculino. Samara Calixto concorda e afirma ser "importante para criação de vínculo de confiança, empatia e respeito, pois acabamos nos colocando na situação delas. Isso ajuda a deixar a modelo mais à vontade". Resposta semelhante a de Camille Alex, sobre a questão: 
Quando fotografo outra mulher, também está em jogo o quelquem eu sou. Acredito que somente outra mulher possui a real perspectiva de outra. Mulheres que fotografam mulheres são capazes de uma verdadeira retratoterapia, porque vivem, sentem e são. Nenhum homem conseguiria entender, vivenciar e captar verdadeiramente uma essência feminina, simplesmente porque não é e não o vive. Fotografamos com a perspectiva do que somos e vivemos (Camille Alex em resposta ao questionário, grifo nosso).

Sobre a questão da representação do corpo feminino pelo olhar masculino versus feminino Teresa Arcq (2016), curadora da exposição Frida Kahlo: conexões entre mulheres surrealistas no México, compara um nu de Frida Kahlo feito por Diego Riviera em 1930 e um autorretrato da artista feito após um de seus abortos, em 1932. Paulo Miyada e Agnaldo Farias (2015) ao estudar o acontecimento ressaltam que apesar de a modelo ser a mesma, com apenas dois anos de intervalo, a diferença entre as imagens é gritante: de um lado está uma mulher cujo corpo, mesmo com suas idiossincrasias retratadas, cabe em um arquétipo romantizado e impessoal - mais geral de ideal feminino sensual e oferecido ao olhar masculino e outro que parece mais fiel à sua singularidade como pessoa.

Pollianna Jamacaru aponta que mulheres que se fotografam fortalecem a "Sororidade e desmistificação do olhar cansado do viés comercial e sexual de exploração do corpo feminino como objeto de desejo, de produto e de medo”. Lícia Maia complementa afirmando que mulheres se fotografarem é fundamental para que se possa:

\footnotetext{
Romper padrões machistas que ainda aprisionam nossos corpos e tomam de conta da arte. Quando uma mulher fotografa outra há um conforto e um realismo maior, é como se uma refletisse a outra, e isso refletisse nas fotos. [...] em todas as questões, nós nos sentimos mais confortáveis diante de outras mulheres [...] (Transcrição da entrevista com Lícia Maia).
}

Dentro do que foi exposto, se observa que o corpo da mulher vai além da matéria bruta e da subjetividade expressiva, sendo, pois, o próprio elemento de construção de significação. Teresa de Lauretis (1994) permite chaves de entendimento sobre as construções representativas de feminilidades, as quais são focalizadas e direcionadas para uma natureza sexual e sedutora, afirmando que essa feminilidade não é essência, não é uma qualidade ou uma propriedade da mulher, mas um conjunto construído de representações baseado no modelo fálico de desejo e significação.

Para Maria Thereza Soares, Márcia Feitosa e José Ferreira Júnior (2018), na contemporaneidade o corpo humano cumpre papel essencial na criação de sentido no autorretrato, pois é nele que se configuram sentimentos e sensações. Corpo esse biológico, mas também social e cultural - indissociável do pensamento. O corpo pós-moderno é 
idealizado, padronizado e narcisista, um corpo-mercadoria, como explictam Kalyla Maroun e Valdo Vieira (2008).

A obsessão do corpo perfeito faz com um número cada vez maior de pessoas se submeta a alterações protéticas e mutilações, seguindo, portanto, a lógica capitalista e midiática, além da recente necessidade da fotogenia e produção constante na era dos selfies. Sobre o corpo glorificado, Lucia Santaella (2004), problematiza que: “a palavra de ordem está no corpo forte, belo, jovem, veloz, preciso, perfeito, inacreditavelmente perfeito" (p. 127).

Atualmente as situações que envolvem corpos diversos, o preconceito de raça e gênero e outros permeiam discussões sobre uso de espaços e exposição desses corpos, para Dorotea Gomes Grijalva (2020) o corpo é um território político, “como um território com história, memória e conhecimentos, tanto ancestrais quanto próprios, da minha história íntima" (p. 10). Ela declara assumir seu corpo deste modo, por entendê-lo enquanto histórico e não biológico, "nomeado e construído a partir de ideologias, discursos e ideias que justificaram sua opressão, exploração, submissão, alienação e desvalorização" (p. 10).

Esta idealização e submissão que tentam nos impor e que buscam regular nossos corpos e afetos tem como consequência mais drástica a morte de mulheres, apenas por serem mulheres, o que se tipifica enquanto feminicídio. Em 2019 o número de casos de feminicídio aumentou 7,3\% em comparação com ano de 2018, foram 1.314 mulheres mortas no Brasil ano passado, uma a cada 7 (sete) horas, em média (Clara VELASCO; Gabriela CAESAR; Thiago REIS, 2020).

O estado do Ceará ocupou em 2018 o $4^{\circ}$ lugar entre os estados brasileiros com maior número de feminicídios, grande parte destas mortes ocorreram na Região do Cariri, lócus desse estudo. De acordo com dados levantados em 2016 nas Delegacias da Defesa da Mulher dos municípios de Juazeiro do Norte e Crato, foram registradas 1933 ocorrências entre janeiro e fevereiro do mesmo ano, apenas nos três principais municípios da região, Crato, Juazeiro e Barbalha (Rodolfo SANTANA, 2019).

Neste território e em tantos outros, a vida da mulher representa uma vida matável, descartável, como aponta Judith Butler (2016): "se certas vidas não são qualificadas como vidas ou se, desde o começo, não são concebíveis como vidas de acordo com certos enquadramentos epistemológicos" (p. 13), mas também políticos, econômicos, religiosos, de gênero, então essas vidas nunca serão vividas nem perdidas no sentido pleno dessas palavras. 
São, portanto, os enquadramentos que decidem, diferenciam e definem quais vidas podem ser apreendias e reconhecíveis como vida e, quais vidas nunca reunirão condições de serem reconhecidas como tal. É, também, por meios dos enquadramentos que se tem à disposição que, segundo ela, entende-se a precariedade da vida. Assim, afirmar que uma vida é precária, significa não apenas apreendê-la como vida, mas também a precariedade como um aspecto no que está vivo. Outro importante aspecto ressaltado por Butler (2016), em sua análise, é que, nos enquadramentos que definem uma vida, ela só é considerada como tal na medida em que é digna de ser enlutada. Ou seja, a vida só tem valor, quando ela é passível de luto (p. 32), e todo luto é atribuído à perda de algo que possui valor ou alguma correspondência afetiva, do contrário, torna-se indiferente.

\section{Considerações Finais}

Ao longo da trajetória da pesquisa revisita-se conceitos e elabora-se uma articulação entre memória e fotografia na contemporaneidade, reflete-se acerca da fotografia para a construção e reconstrução da história - um processo que não é linear e nem isento de influências sócio-políticas e individuais -. Estabelece-se como foco os atravessamentos/ implicações de ser mulher na sociedade, na fotografia e no campo das artes em geral e como nossa história está marcada pelo apagamento de nossas memórias e pelas desigualdades e subalternidades geradas a partir de relações de poder que dominam os espaços públicos e privados em que se percebem avanços e retrocessos quanto à questão de gênero.

Ao buscar articular as discussões de gênero à questão da fotografia percebeu-se estar diante de um desafio tanto na prática e em nível local quanto no campo teórico, a partir das obras que localizávamos. Na atuação e localmente já era possível perceber pela atuação profissional da autora e pelo diálogo com outras mulheres e homens que fotografam na Região do Cariri. Mas a dificuldade em chegar a dados sobre mulheres que atuaram com fotografia no Brasil, e especialmente sobre as mulheres que foram protagonistas neste ofício pareceu ainda mais complexa.

Partiu-se da experiência da primeira Mostra de Mulheres Fotógrafas do Cariri e que esta seria uma oportunidade para problematizar e compreender questões relevantes para o campo e traçar um perfil profissional sobre cada uma das fotógrafas. Mas, talvez num nível maior do que se esperava num primeiro momento da pesquisa, mobilizou-as a refletir - em maior ou menor intensidade - sobre suas motivações, sua relação com a fotografia, sua 
percepção sobre o reconhecimento de seu trabalho, suas experiências etc. Esse trabalho foi ainda uma oportunidade de rememorar histórias e motivações para atuação na fotografia e conhecer as obras de tantas outras mulheres. No estudo e na elaboração das biografias de cada uma dessas mulheres, pode-se contemplar os históricos e assim observar o percurso individual e também coletivo por meio das contribuições destas para a memória da Região, que também precisa ser composta pelos olhares e expressões destas mulheres, compreendidas a partir de sua diversidade.

Ressalta-se, dentre os resultados, a relevância da I Mostra de Mulheres Fotógrafas do Cariri, por ter sido um espaço de encontro e visibilização das fotógrafas do território, que além da qualidade técnica e da sensibilidade artística, construíram a partir da pluralidade de perfis e experiências das participantes uma (re)construção da história e memória local. Após o levantamento e análise dos dados, destaca-se também o Foto Síntese como um dos principais espaços de diálogo e estímulo à fruição, produção e reflexão da fotografia no Cariri Cearense.

Espera-se que esta pesquisa possa contribuir para a visibilização das mulheres no campo da fotografia, especialmente na Região do Cariri e sua atuação enquanto autoras e coparticipes da história local e o reconhecimento da contribuição de suas obras para as memórias do território.

\section{Referências}

ALMEIDA, Sandra R. Goulart de. Prefácio - Apresentando Spivak. In: SPIVAK, Gayatri C. Pode o subalterno falar? 1. ed. Tradução Sandra R. Goulart Almeida, Marcos Pereira Feitosa e André Pereira. Belo Horizonte: Editora da UFMG, 2010.

ARANDAS, Luciana Pionório Rocha de. Por dentro da hashtag Body Positive: ciberativismo e a emergência de uma nova visão do corpo nas redes sociais da internet. In: ENCONTRO ANUAL DA ANPOCS, 42 , 2018, Caxambu. Anais [...]. Caxambu: Associação Nacional de Pós-Graduação e Pesquisa em Ciências Sociais - ANPOCS, 2018, p. 1-24. Disponível em: http://www.anpocs.com/index.php/encontros/papers/42-encontro-anual-da-anpocs/spg5/spg24-3/11587-por-dentro-da-hashtag-body-positive-ciberativismo-e-a-emergencia-de-umanova-visao-do-corpo-nas-redes-sociais-da-internet?path=42-encontro-anual-da-anpocs/spg5/spg24-3. Acesso em 04 set. 2019.

ARCQ, Teresa. Mulheres para mulheres, mecenas e promotoras. Texto expográfico do catálogo da Mostra "Frida Kahlo: conexões entre mulheres surrealistas no México", 2016.

BARDIN, Laurence. Análise de conteúdo. Tradução Luís Antero Retos, Augusto Pinheiro. São Paulo: Edições, v. 70, 2011.

BEAUVOIR, Simone. O segundo sexo. 6. ed. Rio de Janeiro: Nova Fronteira, 2019.

BOURDIEU, Pierre. A Dominação Masculina. Rio de Janeiro: Bertrand Brasil, 2003. 
BUITONI, Dulcilia Schroeder. Fotografia e Jornalismo: a informação pela imagem. São Paulo: Saraiva, 2011.

BUTLER, Judith. Quadros de Gerra: quando a vida é passível de luto?. Tradução Sérgio Tadeu de N. Lamarão e Arnaldo M. da Cunha. Rio de Janeiro: Civilização Brasileira, 2016.

CORREIA, Maria da Luz; CERQUEIRA, Carla. Desarrumando o nosso álbum: fotografia e género. Comunicação e Sociedade, Braga, v. 32, p. 9-17, dez. 2017. DOI:

http://dx.doi.org/10.17231/comsoc.32(2017).2747. Disponível em

http://www.scielo.mec.pt/scielo.php?script=sci_arttext\&pid=S2183-

35752017000200001\&lng=pt\&nrm=iso. Acessos em 06 fev. 2020.

FAJARDO-HILL, Cecília; GIUNTA, Andrea. Mulheres radicais: arte latino-americana, 1965-1980. São Paulo: Pinacoteca de São Paulo, 2018.

FEMEN. Blog oficial da Femen. [s.d.]. Disponível em: https://femen.org/. Acesso em: 14 fev. 2019.

FRASER, Márcia Tourinho Dantas; GONDIM, Sônia Maria Guedes. Da fala do outro ao texto negociado: discussões sobre a entrevista na pesquisa qualitativa. Paidéia (Ribeirão Preto), Ribeirão Preto, v. 14, n. 28, p. 139-152, ago. 2004. DOI:

http://dx.doi.org/10.1590/S0103-863X2004000200004. Disponível em:

http://www.scielo.br/scielo.php?script=sci_arttext\&pid=S0103-

863X2004000200004\&lng=en\&nrm=iso. Acesso em: 03 maio 2019.

GRIJALVA, Dorotea Gómez. Meu corpo é um território político. Tradução Sandra Bonomini. Rio de Janeiro: Zazie Edições, 2020. (Pequena Biblioteca de Ensaios Perspectiva Feminista).

HALBWACHS, Maurice. A memória coletiva. Tradução de Beatriz Sidou. $2^{a}$ ed. São Paulo: Centauro, 2013.

HOLLANDA, Heloisa Buarque de. Explosão Feminista: Arte, Cultura, Política e Universidade. São Paulo: Companhia das Letras, 2018.

HUYSSEN, Andréas. Culturas do passado-presente: modernismos, artes visuais, políticas da memória. Rio de Janeiro: Contraponto, 2014.

INSTITUTO DE PESQUISA ECONÔMICA APLICADA - IPEA, FÓRUM BRASILEIRO DE SEGURANÇA PÚBLICA - FBSP. Atlas da Violência 2019. Rio de Janeiro: IPEA/FBSP, 2019. Recuperado de http://www.forumseguranca.org.br/wp-content/uploads/2019/06/Atlasda-Violencia-2019_05jun_vers\%C3\%A3o-coletiva.pdf

JAGGAR, Alison M.; BORDO, Susan R.; FREITAS, Britta Lemos. Gênero, corpo, conhecimento. Rio de Janeiro: Rosa dos Tempos, 1997.

KETZER, Patricia. Como pensar uma Epistemologia Feminista? Surgimento, repercussões e problematizações. Argumentos Revista de Filosofia, Fortaleza, ano 9, n. 18, p. 95-106, 2017. Disponível em: http://www.repositorio.ufc.br/bitstream/riufc/32159/1/2017_art_pketzer.pdf. Acesso em: 08 jan. 2020. 
LAURETIS, Teresa de. A tecnologia do gênero. In: HOLLANDA, Heloisa Buarque de. Tendências e impasses: o feminismo como crítica da cultura. Rio de Janeiro: Rocco, 1994. p. 206-242.

LONGINO, Helen. Epistemologia Feminista. In: GRECO, John; SOSA, Ernest (Orgs.). Compêndio de epistemologia. Tradução Alessandra Siedschlag Fernandes e Rogério Bettoni. São Paulo: Edições Loyola, 2012.

MAROUN, Kalyla; VIEIRA, Valdo. Corpo: uma mercadoria na pós-modernidade. Psicologia em Revista, Belo Horizonte, v. 14, n. 2, p. 171-186, dez. 2008. Disponível em http://pepsic.bvsalud.org/scielo.php?script=sci_arttext\&pid=S1677-

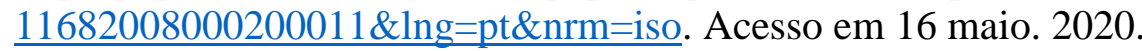

MIGUEL, Sylvia. Representatividade feminina no sistema artístico precisa ser mais bem avaliada. Instituto de Estudos Avançados da Universidade de São Paulo, São Paulo, 21 mar. 2017. Disponível em: http://www.iea.usp.br/noticias/representatividade-feminina-no-sistemaartistico-precisa-ser-melhor-avaliada. Acesso em: 11 fev. 2019.

MIYADA, Paulo; FARIAS, Agnaldo. Frida Kahlo: conexão entre mulheres surrealistas no México. São Paulo: Instituto Tomie Othake, 2015.

NASCIMENTO, Diego Coelho do. Ser-tão “metropolitano": espacialidade e institucionalidade na Região Metropolitana do Cariri. 2018. Tese (Doutorado em Geografia) Universidade Federal de Pernambuco, Recife, 2018. Disponível em: https://repositorio.ufpe.br/handle/123456789/30438. Acesso em: 02 jan. 2020.

NOCHLIN, Linda. Por que não houve grandes mulheres artistas? São Paulo: Edições Aurora, 2016.

NOGUEIRA, Ricardo José Batista. O Movimento FEMEN: geopolítica e neo-feminismo. Revista de Geopolítica, Manaus, v. 4, n. 1, p. 155-168, 2013. Disponível em: http://www.periodicos.ufam.edu.br/revista-geonorte/article/view/1164/1055. Acesso em: 08 abril 2019.

NORA, Pierre. Tradução de Yara Aun Khoury. Entre memória e história: a problemática dos lugares. Projeto História: Revista do Programa de Estudos Pós-Graduados de História, v. 10, p. 7-28, 1993.

OMOTE, Sadao; PRADO, Paulo Sérgio Teixeira do; CARRARA, Kester. Versão eletrônica de questionário e o controle de erros de resposta. Estudos em Psicologia, Natal, v. 10, n. 3, p. 397-405, dez. 2005. DOI: https://doi.org/10.1590/S1413-294X2005000300008.Disponível em: http://www.scielo.br/scielo.php?script=sci_arttext\&pid=S1413294X2005000300008\&lng=en\&nrm=iso. Acesso em 10 fev. 2019.

POLLOCK, Griselda. Vision and Difference: Femininity, Feminism and the Histories of Art. Londres/Nova York: Routledge, 1988.

QUIVY, Raymond; CAMPENHOUDT, Luc Van. Manual de Investigação em Ciências Sociais. 4. ed. Lisboa: Gradiva, 2005.

RECHENA, Aida. Sociomuseologia e Género: Imagens da Mulher em Exposições de Museus Portugueses. 2011. Tese (Doutoramento em Museologia) - Universidade Lusófona de 
Humanidades e Tecnologias, Lisboa, 2011. Disponível em: http://www.museologiaportugal.net/files/upload/doutoramentos/aida_rechena.pdf. Acesso em: 4 fev. 2019.

REZZUTTI, Paulo Marcelo. Mulheres do Brasil: A história não contada. Rio de Janeiro: Leya, 2018.

RIBEIRO, Djamila. O que é lugar de fala? Belo Horizonte: Letramento, 2019.

RUIZ, Juliana Pacetta; NERIS, Natália; VALENTE, Mariana Giorgetti. Revenge porn como violência de gênero: perspectivas internacionais. In: SEMINÁRIO INTERNACIONAL FAZENDO GÊNERO, 11, 2017, Florianópolis. Anais [...]. Florianópolis: Universidade Federal de Santa Catarina - UFSC, Instituto de Estudos de Gênero - IEG, 2017. Disponível em:

http://www.wwc2017.eventos.dype.com.br/resources/anais/1503434623_ARQUIVO_Fazend oGenero_Revengeporncomoviolenciadegenerofinal.pdf. Acesso em 02 jan. 2020.

SANTAELLA, Lucia. Corpo e comunicação: sintonizada cultura. São Paulo: Paulus, 2004.

SANTANA, Rodolfo. Cariri: com altas taxas de feminicídio, políticas de combate à violência são adotadas. Brasil de Fato, 25 nov. 2019. Disponível em:

https://www.brasildefato.com.br/2019/11/25/cariri-com-altas-taxas-de-feminicidio-politicasde-combate-a-violencia-sao-adotadas. Acesso em 08 mar. 2020.

SATOU, Danilo. A representatividade da mulher na arte. Blog Centro Cultural São Paulo, São Paulo, 18 out. 2018. Disponível em: http://centrocultural.sp.gov.br/site/arepresentatividade-da-mulher-na-arte/. Acesso em: 23 fev. 2019.

SMITH, Ian Haydn. Breve história da fotografia: um guia de bolso para os principais gêneros, obras, temas e técnicas. São Paulo: Gustavo Gili, 2018.

SOARES, Maria Thereza Gomes de Figueiredo; FEITOSA, Márcia Manir Miguel; FERREIRA JUNIOR, José. Um olhar sobre a fotografia feminista brasileira contemporânea. Revista de Estudos Feministas, Florianópolis, v. 26, n. 3, e46645, 2018. DOI:

https://doi.org/10.1590/1806-9584-2018v26n346645. Disponível em

http://www.scielo.br/scielo.php?script=sci_arttext\&pid=S0104026X2018000300209\&lng=en\&nrm=iso. Acesso em 06 fev. 2020.

SPIVAK, Gayatri C. Pode o subalterno falar? 1. ed. Tradução Sandra R. Goulart Almeida, Marcos Pereira Feitosa e André Pereira. Belo Horizonte: Editora da UFMG, 2010.

TRIGO, Maria Ilda. Guerrilla Girls: mulheres e museus. Contemporânea, Unicamp, 15 mar. 2018. Disponível em: https://www.blogs.unicamp.br/contemporanea/2018/03/15/guerrillagirls-mulheres-e-museus-v-4-n-3-2018/. Acesso em 08 maio 2020.

VELASCO, Clara; CAESAR, Gabriela; REIS, Thiago. Mesmo com queda recorde de mortes de mulheres, Brasil tem alta no número de feminicídios em 2019. G1 - Globo.com, 05 mar. 2020. Disponível em: https://g1.globo.com/monitor-da-violencia/noticia/2020/03/05/mesmocom-queda-recorde-de-mortes-de-mulheres-brasil-tem-alta-no-numero-de-feminicidios-em2019.ghtml. Acesso: 10 mar. 2020.

WOLF, Naomi. O Mito da Beleza: como as imagens de beleza são usadas contra as mulheres. Rio de Janeiro: Rosa dos Tempos, 2018. 